\title{
A systematic review of omega-3 fatty acids and osteoporosis
}

\author{
Tonya S. Orchard ${ }^{1}$, Xueliang Pan ${ }^{2}$, Fern Cheek ${ }^{3}$, Steven W. Ing ${ }^{4}$ and Rebecca D. Jackson ${ }^{4 *}$ \\ ${ }^{1}$ The Obio State University, College of Education and Human Ecology, Department of Human Nutrition, Columbus, OH, USA \\ ${ }^{2}$ The Obio State University, Center for Biostatistics, Columbus, OH, USA \\ ${ }^{3}$ The Obio State University, Prior Health Sciences Library and Center for Knowledge Management, Columbus, OH, USA \\ ${ }^{4}$ The Obio State University, College of Medicine, Division of Endocrinology, Diabetes, and Metabolism, Columbus, OH, USA
}

\section{Abstract}

Some epidemiological evidence suggests that diets high in omega 3 fatty acids ( $n-3$ FAs) may be beneficial for skeletal health. The aim of this systematic review was to determine if randomized controlled trials (RCTs) support a positive effect of $n$ - 3 FAs on osteoporosis. A systematic search was performed in PubMed and EMBASE databases. We included RCTs with skeletal outcomes conducted in adults or children $(>=1$ year old) using $n-3$ FA fortified foods, diets or supplements alone or in combination with other vitamins/minerals, versus placebo. Primary outcomes were incident fracture at any site and bone mineral density (BMD) in $\mathrm{g} / \mathrm{cm}^{2}$. Secondary outcomes included bone formation or resorption markers and bone turnover regulators. A total of 10 RCTs met inclusion criteria. Effect sizes with 95\% confidence intervals were estimated to compare studies across various treatments and outcome measures. No pooled analysis was completed due to heterogeneity of studies and small sample sizes. No RCTs included fracture as an outcome. Four studies reported significant favorable effects of $n-3$ FA on BMD or bone turnover markers. Of these, three delivered $n-3$ FA in combination with high calcium foods or supplements. Five studies reported no differences in outcomes between $n-3$ FA intervention and control groups; one study included insufficient data for effect size estimation. Strong conclusions regarding $n-3$ FAs and bone disease are limited due to the small number and modest sample sizes of RCTs, however, it appears that any potential benefit of $n-3$ FA on skeletal health may be enhanced by concurrent administration of calcium.

Key words: Aged: Bone density: Cognition: Elderly: Nutritional status: Omega-3 fatty acids: Systematic review

\section{Background}

For nearly four decades, polyunsaturated fatty acids (PUFAs) of the omega-3 ( $n-3)$ family have been studied extensively in relation to prevention and treatment of cardiovascular disease ${ }^{(1-5)}$. The health-promoting effects of $n-3$ fatty acids (FAs) may be partially due to their immune-modulating and anti-inflammatory actions ${ }^{(6-8)}$. Although this was first described in cardiovascular disease, the potential role that inflammatory mediators play in a host of other diseases and conditions including metabolic bone diseases such as osteoporosis has caused investigators to extend studies of $n$ - 3 FAs to include skeletal outcomes ${ }^{(9-13)}$.

Osteoporosis is a pervasive public health problem. According to the World Health Organization, osteoporosis affects more than 75 million people in the United States, Europe and Japan. The estimated lifetime risk of hip, vertebral or wrist fractures is approaching 30-40\% in developed countries, a prevalence similar to that of coronary heart disease ${ }^{(14)}$. Chronic inflammation, due in part to increased cytokine expression after menopause and with aging, is one mechanism contributing to the pathogenesis of osteoporosis. Both pro-inflammatory and anti-inflammatory cytokines and hormones interact to regulate osteoblast and osteoclast differentiation and activity. The balance in these systems is central to the pathogenesis of osteoporosis ${ }^{(15,16)}$.

The anti-inflammatory effects of $n$ - 3 FAs are well-known. Recently, a promising association between higher $n$-3 FA intake and improved bone turnover markers and bone mineral density (BMD) in humans has been reported in some $e^{(17-19)}$ but not all ${ }^{(20,21)}$ studies. This has led to interest in $n$-3 FAs as a nutritional factor that may decrease risk for osteoporotic fractures.

PUFAs have two primary physiological functions in humans. First, they are present as phospholipids in membranes and contribute to an optimum lipid bilayer structure to allow for intercellular communication and highly differentiated membrane functions. Second, they are the primary precursors of bioactive lipid mediators, including the eicosanoids, which have autocrine and paracrine actions throughout the body (22,23). Alpha linolenic acid (ALA: 18:3n-3) is the essential $n$-3 FA in humans ${ }^{(23)}$. ALA can be converted to longer chain $n$-3 FAs, eicosapentaenoic acid (EPA) and docosahexaenoic acid (DHA) in most people, but the extent of this conversion appears to be small, especially when intake of $n-6$ FAs is high, 
as is typical in Western diets ${ }^{(24,25)}$. Marine sources provide most of the EPA and DHA found in the diet and incorporated into blood and tissues.

Though the association of $n$ - 3 FAs to bone turnover markers appears promising, the real test of clinical significance is the impact of $n-3$ FAs on osteoporotic fracture. A small number of epidemiological studies investigating the relationship of fish consumption or dietary $n-3$ FA consumption to fracture risk have yielded mixed results. In a large cohort of over 35,000 men and women from the European Prospective Investigation into Cancer and Nutrition (EPIC-Oxford), no differences were found in risk of fracture in those who reported eating fish only compared to those consuming meat plus fish in their typical diet ${ }^{(26)}$. Consumption of both $n-3$ FAs and $n-6$ FAs in relation to osteoporotic fracture risk was investigated in a case-control study of 167 Spanish men and women over 65 years of age hospitalized for fracture versus matched controls. There was no significant association of total $n-3$ FA intake to fragility fracture, but there was a significantly elevated risk of fracture in individuals reporting the highest quartile of $n$ - 6 FA intake $(>18 \mathrm{~g} / \mathrm{d})^{(27)}$. However, in 137,486 postmenopausal women in the Women's Health Initiative consuming small amounts of EPA + DHA, higher n-6 FAs were associated with a modest decrease in total fracture risk, but higher EPA + DHA intake was associated with a small increase in risk of fractures. Interestingly, women with the highest EPA + DHA intake in this cohort also had the lowest calcium and vitamin D intake. No association was noted between ALA or EPA + DHA intake and hip fracture risk ${ }^{(28)}$.

Recently, the relation of various types of $n$ - 3 FAs to hip fracture risk was examined in 522 postmenopausal women and 352 men in the Framingham Osteoporosis Study. Higher ALA consumption was associated with lower hip fracture risk in women, but not men. No relationship was observed between EPA + DHA intake and hip fracture ${ }^{(29)}$. Likewise, researchers in the Cardiovascular Health Study reported that neither fish intake nor EPA + DHA intake were associated with risk for hip fracture in 5045 participants aged 65 or older, and the LA intake of the background diet did not modify this relationship ${ }^{(30)}$. Suzuki et al. examined the impact of diet and lifestyle factors on hip fracture risk in a case-control study of 4573 Japanese elderly. Fish consumption 3-4 times per week was associated with a decreased risk of hip fracture when compared to the referent of $<2$ fish meals per week. However, eating more than 4 fish meals per week did not improve relative risk ${ }^{(31)}$. Thus, epidemiological data regarding PUFAs and risk of total fracture or hip fracture remains equivocal.

Observational studies yield valuable information regarding associations of exposure to disease in free-living populations, but they do not allow strong conclusions to be drawn regarding cause and effect. Therefore, in order to examine the effect of $n-3$ FAs on prevention and/or treatment of osteoporosis, we undertook a systematic review of randomized controlled trials (RCTs) reported in the literature and cataloged electronically from 1946-April, 2011 to determine the effect of $n$-3 FA supplementation on BMD and fractures, and secondarily on regulation of bone turnover.

\section{Materials and Methods}

\section{Criteria for considering studies for this review}

This review was restricted to English language reports of RCTs with skeletal outcomes that were conducted in adults or children ( $>=1$ year old) using $n$-3 FA fortified foods, diets or $n$-3 FA supplements alone or in combination with other vitamins/minerals, compared to placebo. The primary skeletal outcomes of interest were incident fracture at any site and BMD. Secondary skeletal outcomes included bone formation markers [bone specific alkaline phosphatase (BSAP) and osteocalcin (OC)], bone resorption markers [N-terminal telopeptide (NTx), C- terminal telopeptide (CTx), urinary pyridinoline (u-pyr) and urinary deoxypyridinoline (u-dpyr)] and regulators of bone turnover [osteoprotegerin (OPG), receptor activator of NFkB ligand (RANKL), OPG/RANKL].

Studies in which subjects had co-morbidities were included with the exception of co-morbidities that could directly impact both fatty acid absorption and skeletal outcomes (i.e. Crohn's disease, irritable bowel syndrome, ulcerative colitis, celiac disease, cystic fibrosis). There were no restrictions based on gender of participants or race/ethnicity. If allocation of treatment and placebo were not random, studies were excluded.

\section{Search methods for identification of studies}

PubMed® database, including MEDLINE and OLDMEDLINE, was searched on April 14, 2011 and EMBASE database (containing references from 1974 - present) and EMBASE Classic (containing references from 1947-1973) was searched on April 23, 2011. MEDLINE is the primary component of PubMed ${ }^{\circledR}$ and time coverage is generally 1966 to the present. OLDMEDLINE is a subset of PubMed ${ }^{\circledR}$ that contains over 2 million citations from two print indexes: Cumulated Index Medicus and the Current List of Medical Literature from the years 1946 through $1965^{(32)}$. We used the following search strategy: Omega 3 fatty acids or $n-3$ fatty acids or essential fatty acids or eicosapentaenoic fatty acids or EPA or ethylEPA or ethyl eicosapentaenoic fatty acid or docosahexaenoic acid or DHA or docosapentaenoic acid or DPA or alpha linolenic acid or ALA or LNA or polyunsaturated fatty acids, including the MeSH terms: "Fatty Acids, Omega-3"[MeSH] OR "Fatty Acids, Essential"[MeSH]OR "Fatty Acids, Unsaturated" [MeSH] OR "Fish Oils"[MeSH])OR "Fats, Unsaturated"[MeSH] AND bone disease or osteoporosis or osteopenia or fracture, including MeSH terms: "Bone Diseases, Metabolic"[MeSH]OR bone diseases OR osteoporosis OR fracture. Additionally, bibliographies from retrieved papers were checked and reviewers were asked to contribute any other references for consideration.

\section{Quality of evidence and statistical analysis}

Studies meeting inclusion criteria were analyzed separately by two reviewers to evaluate quality of evidence across five categories:(1) risk of bias due to limitations in study design and/or execution such as no allocation concealment, no blinding, selective outcome reporting, intention to treat violation, 
or large loss to follow-up, (2) inconsistency of results considering variation in effect sizes, (3) indirectness of evidence due to differences in populations, interventions and outcomes, (4) publication bias, and (5) imprecision of results due to small number of events or wide confidence intervals. This type of assessment is based on the GRADE system ${ }^{(33,34)}$, but because of heterogeneity of populations, treatments and endpoint measures, studies were not pooled for analysis. After reviewing each study in relation to the five categories, a quality of evidence level was assigned as explained in Table 1. Any discrepancies were resolved by a third independent reviewer.

To compare the magnitude of the effect of $n-3$ FAs on various endpoint measures, we used effect size and its corresponding $95 \%$ confidence interval ${ }^{(35-37)}$ to summarize the differences between treatment and the control. Effect size is the difference between the means of the two groups (M1 - M2) divided by the within-group standard deviation (S): i.e. $(M 1-M 2) / S$. The accuracy of the estimated effect size is quantified by its confidence interval, which is influenced by the sample size. To make conclusions, if the confidence interval of the estimated effect size includes zero, then no statistically significant difference between the two groups was found for that particular endpoint. The absolute magnitude of the effect size indicates its strength: $0 \cdot 2$ suggests a small effect, whereas an effect size of 1.0 indicates a large effect.

\section{Results}

Results of the PubMed ${ }^{\circledR}$ and EMBASE search yielded 122 and 188 papers respectively, of which 24 studies were flagged for potential inclusion based on title and abstract. Of these, nine RCTs met our inclusion criteria. Additionally, a RCT published soon after the initial search was submitted by one of the reviewers and added to the included studies. The 10 RCTs selected for full analysis of quality and effect size are summarized in Table 2. Relevant aspects of study design, including whether skeletal outcomes were analyzed as part of an ancillary study within a larger study or as secondary endpoint measures, are detailed for the reader. Effect size estimates

Table 1. Quality of evidence levels

\begin{tabular}{|c|c|}
\hline Quality Level & Explanation \\
\hline High & $\begin{array}{l}\text { Further research is unlikely to change } \\
\text { our confidence in the estimate of } \\
\text { the effect }\end{array}$ \\
\hline Moderate & $\begin{array}{l}\text { Further research is likely to have } \\
\text { an important impact on our confidence } \\
\text { in the estimate of effect and } \\
\text { may change the estimate }\end{array}$ \\
\hline Low & $\begin{array}{l}\text { Further research is very likely to } \\
\text { have an important impact on our } \\
\text { confidence in the estimate of effect } \\
\text { and is likely to change the } \\
\text { estimate. }\end{array}$ \\
\hline Very Low & $\begin{array}{l}\text { Any estimate of the effect is } \\
\text { very uncertain and we have little } \\
\text { confidence in the estimate }\end{array}$ \\
\hline
\end{tabular}

Adapted from ${ }^{(41,42)}$ with $95 \%$ confidence intervals and the quality of evidence level with footnoted explanations are also included in the table.

Four ${ }^{(8,38-40)}$ of the 10 RCTs had significant positive effect size estimates with $95 \%$ confidence intervals greater than zero, indicative of a positive effect of $n-3$ FA treatment on the endpoint measured compared to control. Five studies $^{(41-45)}$ showed no significant difference in effect size of treatment versus control, and one study ${ }^{(46)}$ did not provide sufficient data for effect size calculation. A moderate quality of evidence level was given to three of the four significant RCTs (See Table 2). A low quality of evidence level was assigned to one $^{(8)}$ of the four RCTs because of a serious risk of bias associated with drop out or exclusion of $>50 \%$ of participants and a small number of final events/participants ( $n$ 21).

\section{Discussion}

This systematic review of RCTs of $n-3$ FAs and bone disease yielded 10 studies for inclusion which reflected heterogeneous populations, treatments and endpoint measures. No RCTs addressing fracture as an outcome were identified. Four studies investigated BMD as a primary outcome, with only one ${ }^{(40)}$ showing significant improvement or maintenance of BMD in a sample of elderly Caucasian South African women with osteopenia or osteoporosis treated with a combination of evening primrose oil (high in linoleic and gamma linolenic acid), fish oil and calcium versus a placebo of coconut oil and calcium for 18 months. The effect size for femoral neck BMD in the trial by Kruger et al. was very large (2.16; $95 \%$ CI $1 \cdot 52$, $2.79)$, with effect on lumbar BMD in the moderate range $(0.75$; $95 \%$ CI $0 \cdot 22,1 \cdot 27)$. The very large effect size seen with femoral neck BMD is likely due in part to the relatively small sample size ( $n 60$ completed study); but it is also possible that the combination of $n-6$ FAs, $n-3$ FAs and 600 mg of calcium carbonate may preferentially impact hip BMD, especially in frail, elderly women. In the Women's Health Initiative, hip BMD, but not total spine BMD, was significantly higher in postmenopausal women taking $1000 \mathrm{mg}$ calcium carbonate and $400 \mathrm{IU}$ of vitamin $\mathrm{D}$ daily versus placebo over 9 years of follow-up ${ }^{(47)}$.

Several factors could have contributed to the beneficial effects observed in the trial by Kruger et al. First, participants may have been especially responsive to the intervention because of their advanced age and nutritional status. BMD decreases with age and age is the most powerful predictor of fracture ${ }^{(48,49)}$. Positive changes in BMD related to $n-3$ FA supplementation may be more easily detected in vulnerable groups of individuals such as this elderly cohort. Additionally, these women were consuming less than the Recommended Dietary Allowance at the time for calcium, magnesium and vitamin $\mathrm{D}$, and according to the researchers, could have been marginally deficient in essential fatty acids prior to study entry. Compromised nutritional status may have contributed to bone frailty and made this cohort more likely to respond to nutritional intervention. Second, participants were initially treated for 18 months. By comparison, other RCTs examining BMD treated participants for 3-12 months (Bassey et al., 2000; Dodin et al., 2005; Cornish \& Chilibeck, 2009), which may not 
Table 2. Summary of randomized controlled trials included in systematic review organized by primary outcome measures

\begin{tabular}{|c|c|c|c|c|c|c|c|c|}
\hline Author & Patient/subjects & $n$ & Study Design & Outcome & Measures* & $\begin{array}{l}\text { Effect Size }(95 \% \\
\mathrm{Cl})\end{array}$ & $\begin{array}{l}\text { Quality } \\
\text { of } \\
\text { Evidence }\end{array}$ & Conclusions \\
\hline \multicolumn{9}{|c|}{ Studies with Bone Mineral Density as Primary Outcome } \\
\hline $\begin{array}{l}\text { Cornish } \\
\text { and Chili- } \\
\text { beck } \\
2009\end{array}$ & $\begin{array}{l}\text { Older healthy adults } \\
\text { (65.4 } \pm 0 \cdot 8 \text { yrs Cana- } \\
\text { dian, 28M, 23F) }\end{array}$ & 51 & $\begin{array}{l}\text { Double blinded randomized } 30 \mathrm{ml} \\
\text { flaxseed oil (14 g ALA, } n 25) \text { vs } \\
\text { corn oil placebo }(n 26) \text { plus resist- } \\
\text { ance training for } 12 \text { wks }\end{array}$ & Primary & $\begin{array}{l}\text { Lumber } \\
\text { BMD } \\
\text { Hip BMD }\end{array}$ & $\begin{array}{r}0.1(-0.45,0.64) \\
0(-0.55,0.55)\end{array}$ & $\operatorname{low}^{1}$ & No significant differences \\
\hline $\begin{array}{l}\text { Dodin et al., } \\
2005\end{array}$ & $\begin{array}{l}\text { Postmenopausal women } \\
\text { in Canada }\end{array}$ & 179 & $\begin{array}{l}\text { Double blinded randomized } 40 \mathrm{~g} / \mathrm{day} \\
\text { flaxseed }(n \text { 85) vs wheat germ pla- } \\
\text { cebo }(n 94) \\
\text { for } 1 \mathrm{yr}\end{array}$ & Primary & $\begin{array}{l}\text { Lumbar } \\
\text { BMD } \\
\text { Femoral } \\
\text { neck BMD }\end{array}$ & $\begin{array}{l}0.22(-0.07,0.52) \\
0.23(-0.06,0.53)\end{array}$ & $\bmod ^{2}$ & No significant differences \\
\hline \multirow[t]{2}{*}{$\begin{array}{l}\text { Kruger } \\
\text { et al., } \\
1998\end{array}$} & \multirow[t]{2}{*}{$\begin{array}{l}\text { Postmenopausal women } \\
\text { with senile osteoporo- } \\
\text { sis (mean age } 79.5 \\
\text { years) in S. Africa }\end{array}$} & \multirow[t]{2}{*}{60} & \multirow[t]{2}{*}{$\begin{array}{l}\text { Randomized evening primrose oil }+ \\
\text { fish oil }+ \text { calcium }(n \text { 29) vs coconut } \\
\text { oil }+ \text { calcium placebo }(n 31) \text { for } 18 \\
\text { months }\end{array}$} & Primary & $\begin{array}{l}\text { Lumbar } \\
\text { BMD } \\
\text { Femoral }\end{array}$ & $\begin{array}{l}0.75(0.22,1 \cdot 27) \\
2 \cdot 16(1.52,2 \cdot 79)\end{array}$ & \multirow[t]{2}{*}{$\bmod ^{3}$} & \multirow{2}{*}{$\begin{array}{l}\text { A combination of GLA, EPA, DHA, } \\
\text { LA and calcium may maintain } \\
\text { lumbar and increase femoral neck } \\
\text { BMD compared to coconut oil and } \\
\text { calcium }\end{array}$} \\
\hline & & & & Secondary & $\begin{array}{l}\text { OC } \\
\text { BSAP } \\
\text { Dpyr }\end{array}$ & $\begin{array}{r}-0.14(-0.64,0.37) \\
0.04(-0.47,0.54) \\
0.29(-0.22,0.79)\end{array}$ & & \\
\hline \multirow[t]{2}{*}{$\begin{array}{l}\text { Bassey } \\
\text { et al., } \\
2000\end{array}$} & $\begin{array}{l}\text { Healthy premenopausal } \\
\text { women }(34-35 \mathrm{yr}) \text { in } \\
\text { UK }\end{array}$ & 43 & $\begin{array}{l}\text { Double blinded randomized Efacal } \\
(4 \mathrm{~g} \text { evening primrose oil, } 440 \mathrm{mg} \\
\text { fish oil, } 1 \mathrm{~g} \text { calcium; } n 19) \mathrm{vs} 1 \mathrm{~g} \\
\text { calcium control }(n 24) \text { for } 1 \mathrm{yr}\end{array}$ & $\begin{array}{l}\text { Primary } \\
\text { Secondary }\end{array}$ & $\begin{array}{l}\text { Total BMD } \\
\text { OC } \\
\text { NTX } \\
\text { BSAP }\end{array}$ & $\begin{aligned}-0.34 & (-0.94,0.27) \\
0 & (-0.61,0.6) \\
-0.12 & (-0.72,0.48) \\
0.26 & (-0.35,0.86)\end{aligned}$ & $\operatorname{low}^{4}$ & No significant differences \\
\hline & $\begin{array}{l}\text { Healthy postmenopausal } \\
\text { women }(55-58 \mathrm{yr}) \text { in } \\
\text { UK }\end{array}$ & 45 & $\begin{array}{l}\text { Double blinded randomized Efacal ( } n \\
21) \text { vs calcium control } \\
(n 24) \text { for } 1 \mathrm{yr}\end{array}$ & $\begin{array}{l}\text { Primary } \\
\text { Secondary }\end{array}$ & $\begin{array}{l}\text { Total BMD } \\
\text { OC } \\
\text { NTX } \\
\text { BSAP }\end{array}$ & $\begin{aligned} 0.42 & (-0.19,1.03) \\
-0.52 & (-1.13,0 \cdot 1) \\
-0.26 & (-0.87,0.35) \\
0.04 & (-0.57,0.64)\end{aligned}$ & low $^{4}$ & No significant differences \\
\hline \multicolumn{9}{|c|}{ Studies with Bone Formation/Resorption Markers as Primary Outcome } \\
\hline $\begin{array}{l}\text { Appleton } \\
\text { et al., } \\
2011\end{array}$ & $\begin{array}{l}\text { Mild-moderately } \\
\text { depressed adults (total } \\
190, \text { only } 113 \text { in the } \\
\text { analysis, 26M, 87F) in } \\
\text { UK }\end{array}$ & 113 & $\begin{array}{l}\text { Double blinded, randomized to } 1.48 \mathrm{~g} \\
\text { EPA + DHA ( } n \text { 53) vs olive oil pla- } \\
\text { cebo }(n 60) \text { for } 12 \text { wks }\end{array}$ & $\begin{array}{l}\text { Ancillary } \\
\text { data } \\
\text { analysis }\end{array}$ & $\begin{array}{l}\text { Serum } \beta- \\
\text { CTX }\end{array}$ & $0.05(-0.32,0.42)$ & low $^{5}$ & No significant differences \\
\hline $\begin{array}{l}\text { Salari et al., } \\
2010\end{array}$ & $\begin{array}{l}\text { Postmenopausal women } \\
\text { in Iran }\end{array}$ & 25 & $\begin{array}{l}\text { Blinded, randomized to } 900 \mathrm{mg} \\
\text { omega } 3 \text { FA }(n \text { 13) vs unidentified } \\
\text { placebo }(n 12) \text { for } 6 \text { months }\end{array}$ & Primary & $\begin{array}{l}\text { Serum OC } \\
\text { Serum } \\
\text { BSAP }^{\star *} \\
\text { UPyr }^{\star *}\end{array}$ & $\begin{array}{r}0.22(-0.56,1.01) \\
-0.37(-1.17,0.42) \\
0.32(-0.47,1.11)\end{array}$ & very low ${ }^{6}$ & No significant differences \\
\hline $\begin{array}{l}\text { Dawczynski } \\
\text { et al., } \\
2009\end{array}$ & $\begin{array}{l}\text { Rheumatoid arthritis } \\
\text { patients in Germany } \\
(43 \mathrm{~F}, 2 \mathrm{M})\end{array}$ & 45 & $\begin{array}{l}\text { Double blinded, randomized cross- } \\
\text { over design omega } 3 \text { fortified dairy } \\
(1.1 \mathrm{~g} \mathrm{ALA}, 0.7 \mathrm{~g} \text { EPA, } 0.4 \mathrm{~g} \text { DHA) } \\
\text { vs standard dairy products in diet } \\
\text { for } 12 \text { wks and } 8 \text { wks washout }\end{array}$ & $\begin{array}{l}\text { One of } \\
\text { Primary } \\
\text { end- } \\
\text { points }\end{array}$ & $\begin{array}{l}\mathrm{Pyr} / \mathrm{Cr} \\
\mathrm{Dpyr} / \mathrm{Cr}\end{array}$ & $\begin{array}{r}0.35(-0.26,0.96) \\
0.89(0.25,1.52)\end{array}$ & $\operatorname{low}^{7}$ & $\begin{array}{l}\text { Dairy products fortified with ALA, } \\
\text { EPA and DHA may decrease a } \\
\text { urinary marker of bone resorption } \\
\text { compared to standard dairy } \\
\text { products }\end{array}$ \\
\hline $\begin{array}{l}\text { Griel et al., } \\
2007\end{array}$ & $\begin{array}{l}\text { Hyperlipidemic adults } \\
(48 \cdot 6 \pm 1 \cdot 6 \text { year, } 20 \mathrm{M}, \\
\text { 3F) in US }\end{array}$ & 23 & $\begin{array}{l}\text { Double blinded, randomized three } \\
\text { period crossover design Average } \\
\text { American, LA, ALA diet with } 6 \mathrm{wk} \\
\text { diet, } \sim 3 \mathrm{wk} \text { washout }\end{array}$ & $\begin{array}{l}\text { Ancillary } \\
\text { data } \\
\text { analysis }\end{array}$ & $\begin{array}{l}\text { NTX } \\
\text { BSAP }\end{array}$ & $\begin{array}{r}1.94(1 \cdot 24,2 \cdot 64) \\
0.2(-0.38,0 \cdot 77)\end{array}$ & $\bmod ^{8}$ & $\begin{array}{l}\text { A high ALA diet may decrease a } \\
\text { marker of bone resorption } \\
\text { compared to average } \\
\text { American diet }\end{array}$ \\
\hline Studies var & Regulato & $r T$ & ary Outcome & & & & & \\
\hline $\begin{array}{l}\text { Martin-Bau- } \\
\text { tista } \\
\text { et al., } \\
2010\end{array}$ & $\begin{array}{l}\text { Hyperlipidemic patients in } \\
\text { Spain }(35-65 y)\end{array}$ & 72 & $\begin{array}{l}\text { Double blinded randomized to forti- } \\
\text { fied milk with fish oil }(0.06 \mathrm{~g} \text { ALA, } \\
0.2 \mathrm{~g} \text { EPA, } 0.14 \mathrm{~g} \text { DHA }) \text { oleic acid } \\
\text { and vitamins }(n 39) \text { vs standard } \\
\text { milk control }(n 33) \text { for } 1 \mathrm{yr}\end{array}$ & $\begin{array}{l}\text { Ancillary } \\
\text { data } \\
\text { analysis }\end{array}$ & $\begin{array}{l}\text { OPG } \\
\text { RANKL } \\
\text { OPG/RANKL } \\
\text { OC } \\
\text { CTX }\end{array}$ & $\begin{array}{r}2.92(2 \cdot 26,3.59) \\
0.71(0.23,1 \cdot 19) \\
0.27(-0.2,0.74) \\
4 \cdot 34(3 \cdot 5,5 \cdot 19) \\
0.03(-0.43,0.5)\end{array}$ & $\bmod ^{9}$ & $\begin{array}{l}\text { Milk fortified with fish oil, oleic acid } \\
\text { and vitamins may improve } \\
\text { regulators of bone turnover } \\
\text { compared to standard milk }\end{array}$ \\
\hline
\end{tabular}


be enough time to see changes in BMD at some skeletal sites, especially in a much younger, healthier population. Finally, including $n-3$ FAs with $n-6$ FAs and calcium carbonate may have promoted a synergistic effect on bone.

A beneficial interaction between calcium and $n-3$ FAs is plausible based on work done mainly in animal and in vitro models suggesting up-regulation of duodenal calcium absorption and decreased calcium excretion with treatment of $n-3$ FAs ${ }^{(50-52)}$. Three $e^{(40)(8,38)}$ of the four RCTs in this review with significant positive effects on skeletal outcomes lend support to this hypothesis. As previously discussed, Kruger et al. used a calcium supplement in addition to $n-6$ plus $n-3$ FAs, while two additional RCTs delivered $n-3$ FAs in fortified dairy products also high in calcium, vitamins and minerals. Martin-Bautista et al. reported increased OPG, RANKL, OPG/RANKL and osteocalcin in hyperlipidemic patients receiving milk fortified with fish oil, oleic acid and vitamins A, B6, D, E and folic acid(38). Our effect size estimates for OPG and OC endpoints from this study were very large (2.92; $95 \%$ CI $2 \cdot 26,3.59$ and $4.34 ; 95 \%$ CI 3.5, 5.19, respectively), with a moderate effect size estimate $(0 \cdot 71 ; 95 \%$ CI $0 \cdot 23,1 \cdot 19)$ for RANKL. There were also a moderate number of participants in this study $(n$ 72) which may inflate effect size estimates.

Differences in race/ethnicity and culture between South African, French Canadian, American, Northern European, Southern European and Middle Eastern subjects may also have contributed to varying results of these RCTs. Race/ ethnicity impacts $\mathrm{BMD}^{(48)}$ and is a known risk factor for fractures. For example, white women have about a $60 \%$ higher risk for hip fractures than black women and about a $75 \%$ higher risk than Asian/Pacific Island women ${ }^{(49)}$. One of the limitations of most of the reviewed RCTs is the failure to report the racial/ethnic background of the participants. Future studies investigating $n$-3 FAs and skeletal health need to address the paucity of data in multi-ethnic cohorts.

The source of $n-3$ FAs may also have a significant impact on skeletal health. When EPA + DHA were given alone (excluding concomitant administration with calcium and vitamins), there was no beneficial effect noted in RCTs in this review. In contrast, a diet high in ALA from addition of walnuts, walnut oil and flaxseed oil compared to an average American diet pattern decreased NTx, a marker of bone resorption ${ }^{(39)}$. Additionally, a mixture of plant and marine sources of $n-3$ FAs, with ALA in highest quantity, was used to fortify dairy products with the resultant decrease in u-Dpyr, a urinary marker of bone resorption $^{(8)}$. Recent evidence from observational studies links higher ALA intake ${ }^{(29)}$ and ALA in red blood cells (unpublished data, Orchard, T.) with reduced risk of hip fracture. It is possible that ALA, EPA and DHA have differential effects on bone turnover. It is also important to consider the oils or foods used as placebos for $n$-3 FA trials. Saturated, monounsaturated and $n-6$ polyunsaturated fatty acids found in various ratios in olive oil, corn oil, coconut oil and wheat germ (all placebos used in RCTs in this review) may impact inflammatory pathways, calcium absorption, bone turnover and BMD differentially, making the detection of an effect from $n$-3 FA intervention more or less likely depending on the choice of 
placebo. Two of the reviewed RCTs with positive outcomes used standard dairy products as a placebo ${ }^{(8)}$ one used coconut oil plus calcium ${ }^{(40)}$ and one used a controlled feeding crossover design comparing three diets ${ }^{(39)}$.

Of the several potential mechanisms whereby $n-3$ FAs may impact bone, two of the most well-defined involve decreasing pro-inflammatory cytokines critical to regulation of bone turnover and modulating calcium balance. Cytokines are key regulators of the osteoprotegerin/receptor activator of NFKB ligand (OPG/RANKL) ratio in bone ${ }^{(15)}$. RANKL is expressed in osteoblasts and activates its receptor, RANK, which is expressed on osteoclasts, thus promoting osteoclast formation and activation, as well as suppressing apoptosis of osteoclasts. Osteoprotegerin (OPG) is a secretory glycoprotein expressed by osteoblasts which blocks RANKL from activating RANK. The ratio of OPG/RANKL is critical in the pathogenesis of resorptive bone disease, with a higher ratio indicating less bone resorption ${ }^{(15)}$.

The effect of $n$-3 FAs on nuclear factor-kappaB (NF-кB) has been examined in vitro. Pre-treatment of osteoclasts with EPA decreased tumor necrosis factor $\alpha$ (TNF $\alpha$ )-induced NF- $\mathrm{B}$ protein expression and activation in a dose-dependent manner ${ }^{(53)}$. The $n-3$ FAs have been shown to decrease production of the $n-6$ FA derived eicosanoid, prostaglandin $\mathrm{E}_{2}$ $\left(\mathrm{PGE}_{2}\right),{ }^{(54,55)}$ and increase bone formation markers, alkaline phosphatase and osteocalcin ${ }^{(11)}$. High $\mathrm{PGE}_{2}$ decreases OPG production and increases RANKL expression ${ }^{(15)}$. DHA added to osteoblastic cell cultures does not stimulate RANKL, but the $n-6 \mathrm{FA}$, arachidonic acid, stimulates RANKL and inhibits OPG secretion by $25-30 \%$ thus reducing the OPG/RANKL ratio $^{(17)}$. There was a relatively large positive effect on OPG and osteocalcin in subjects consuming milk fortified with $n$ 3 FAs, oleic acid and vitamins (Martin-Bautista et al., 2010). These data suggest that there is an optimum balance of $n-3$ and $n-6$ FAs needed to promote a less inflammatory cytokine environment favorable to bone remodeling.

A second possible mechanism by which $n$-3 FAs may influence bone is related to up-regulation of intestinal calcium absorption. Essential FAs are necessary for maximal vitamin D-dependent calcium absorption ${ }^{(50)}$. DHA and EPA decrease urinary calcium excretion in a rat model of osteoporosis exacerbated by restricted food intake ${ }^{(52)}$ and in patients with idiopathic calcium nephrolithiasis, fish oil decreases urinary calcium excretion and returned the high level of calcium absorption toward normal ${ }^{(55)}$. In vitro and animal studies show up-regulation of duodenal calcium absorption by DHA via modulating Calcium-ATPase when calcium levels are low ${ }^{(51,56)}$. In ovariectomized rats, calcium-ATPase activity at the intestinal basolateral membrane increases significantly following supplementation with essential FAs in a ratio of $1 / 3$, GLA/EPA + DHA. ${ }^{(57)}$. Thus, the essential $n-3$ and $n-6$ FAs may act to increase calcium absorption and decrease calcium excretion, especially when dietary calcium intake is low.

\section{Conclusions}

In summary, an $n-3$ and $n-6$ FA mixture combined with calcium, n-3 FA fortified dairy products, and a high ALA diet resulted in statistically significant positive effects on bonerelated outcomes in diverse individuals in four RCTs in this review. However, five RCTs showed no significant effects of $n$-3 FA intervention. Due to the small number of RCTs and the heterogeneity of the studies, we are unable to make strong conclusions regarding supplementation of $n-3$ FAs and skeletal health. Although there is insufficient evidence to support a positive relation between $n-3$ FA and prevention or treatment of osteoporosis at this time, it appears that any benefit might be enhanced by inclusion of $n-3$ FAs in foods high in calcium, vitamins and minerals, or in concentrated oil mixtures with other PUFAs and calcium. To definitively address the role of both plant-based and marine sources of $n-3$ FAs for reducing risk for osteoporosis, there is a need for further large scale investigation of the differential effects of various $n$-3 FAs in relation to skeletal outcomes, particularly fracture.

\section{Acknowledgements}

Contribution of Authors: TO and FC searched databases. TO and RJ determined studies for inclusion, reviewed literature, graded evidence, prepared manuscript. TO and XP extracted data. XP performed statistical analysis. SI arbitrated graded evidence and reviewed manuscript. FC reviewed manuscript. There is no conflict of interest. Source of Funding: The project described was supported by Award Number UL1RR025755 from the National Center for Research Resources. The content is solely the responsibility of the authors and does not necessarily represent the official views of the National Center For Research Resources or the National Institutes of Health. The WHI program is funded by the National Heart, Lung, and Blood Institute, National Institutes of Health, U.S. Department of Health and Human Services through contracts N01WH22110, 24152, 32100-2, 32105-6, 32108-9, 32111-13, 32115, 32118-32119, 32122, 42107-26, 42129-32, and 44221.

\section{References}

1. Dyerberg J, Bang HO, Stoffersen E, et al. (1978) Eicospentaenoic acid and prevention of thrombosis and atherosclerosis? The Lancet 312, 8081, 117-119.

2. Bang HO, Dyerberg J \& Sinclair HM (1980) The composition of the Eskimo food in north western Greenland. Am J Clin Nutr 33, 12, 2657-2661.

3. Bang HO \& Dyerberg J (1987) Fatty acid pattern and ischaemic heart disease. Lancet 1, 8533, 633.

4. Block RC, Harris WS, Reid KJ, et al. (2008) EPA and DHA in blood cell membranes from acute coronary syndrome patients and controls. Atherosclerosis 197, 2, 821-828.

5. Marchioli R, Schweiger C, Tavazzi L, et al. (2001) Efficacy of n-3 polyunsaturated fatty acids after myocardial infarction: results of GISSI-Prevenzione trial. Gruppo Italiano per lo Studio della Sopravvivenza nell'Infarto Miocardico. Lipids Suppl. S1, 36, 19-26.

6. Das UN (2002) Estrogen, statins, and polyunsaturated fatty acids: similarities in their actions and benefits-is there a common link? Nutrition (Burbank, Los Angeles County, Calif.) 18, 2, 178-188. 
7. Simopoulos AP (2002) Omega-3 Fatty Acids in Inflammation and Autoimmune Diseases. J Am Coll Nutr 21, 6, 495-505.

8. Dawczynski C, Schubert R, Hein G, et al. (2009) Long-term moderate intervention with $\mathrm{n}-3$ long-chain PUFA-supplemented dairy products: effects on pathophysiological biomarkers in patients with rheumatoid arthritis. The British journal of nutrition 101, 10, 1517-1526.

9. Ding C, Parameswaran V, Udayan R, et al. (2008) Circulating levels of inflammatory markers predict change in bone mineral density and resorption in older adults: a longitudinal study. J Clin Endocrinol Metab 93, 5, 1952-1958.

10. Cauley JA, Danielson ME, Boudreau RM, et al. (2007) Inflammatory markers and incident fracture risk in older men and women: the Health Aging and Body Composition Study. J Bone Miner Res 22, 7, 1088-1095.

11. Watkins BA, Lippman HE, Le Bouteiller L, et al. (2001) Bioactive fatty acids: role in bone biology and bone cell function. Progress in lipid research 1-2, 40, 125-148.

12. Zhang Y-H, Heulsmann A, Tondravi MM, et al. (2001) Tumor Necrosis Factor-alpha (TNF) Stimulates RANKL-induced Osteoclastogenesis via Coupling of TNF Type 1 Receptor and RANK Signaling Pathways. J Biol Chem 276, 1, 563-568.

13. Kruger MC, Coetzee M, Haag M, et al. (2010) Long-chain polyunsaturated fatty acids: selected mechanisms of action on bone. Progress in lipid research 49, 4, 438-449.

14. WHO (2004) WHO Scientific Group on the Assessment of Osteoporoosis at Primary Health Care Level [cited 2011 June 16, 2011]. Available from: http://www.who.int/chp/ topics/Osteoporosis.pdf

15. Hofbauer LC \& Schoppet M (2004) Clinical Implications of the Osteoprotegerin/RANKL/RANK System for Bone and Vascular Diseases. JAMA 292, 4, 490-495.

16. Boyce BF \& Xing L (2007) Biology of RANK, RANKL, and osteoprotegerin. Arthritis research \& therapy 9, Suppl. 1, S1.

17. Coetzee M, Haag M \& Kruger MC (2007) Effects of arachidonic acid, docosahexaenoic acid, prostaglandin E(2) and parathyroid hormone on osteoprotegerin and RANKL secretion by MC3T3-E1 osteoblast-like cells. The Journal of nutritional biochemistry 18, 1, 54-63.

18. Hogstrom M, Nordstrom P \& Nordstrom A (2007) n-3 Fatty acids are positively associated with peak bone mineral density and bone accrual in healthy men: the $\mathrm{NO}_{2}$ Study. $\mathrm{Am}$ J Clin Nutr 85, 3, 803-807.

19. Weiss LA, Barrett-Connor E \& von Muhlen D (2005) Ratio of n-6 to n-3 fatty acids and bone mineral density in older adults: the Rancho Bernardo Study. Am J Clin Nutr 81, 4, 934-938.

20. Macdonald HM, New SA, Golden MHN, et al. (2004) Nutritional associations with bone loss during the menopausal transition: evidence of a beneficial effect of calcium, alcohol, and fruit and vegetable nutrients and of a detrimental effect of fatty acids. Am J Clin Nutr 79, 1, 155-165.

21. Trebble TM, Stroud MA, Wootton SA, et al. (2005) High-dose fish oil and antioxidants in Crohn's disease and the response of bone turnover: a randomised controlled trial. The British journal of nutrition 94, 2, 253-261.

22. Stipanuk MH, Biochemical and Physiological Aspects of Human Nutrition: W.B. Saunders Company.

23. Albertazzi P \& Coupland K (2002) Polyunsaturated fatty acids. Is there a role in postmenopausal osteoporosis prevention? Maturitas 42, 1, 13-22.

24. Kris-Etherton PM, Taylor DS, Yu-Poth S, et al. (2000) Polyunsaturated fatty acids in the food chain in the United States. Am J Clin Nutr 71, Suppl. 1, 179S-188S.

25. Whelan J \& Rust C (2006) Innovative dietary sources of $n-3$ fatty acids. Annual review of nutrition 26, 75-103.
26. Appleby P, Roddam A, Allen N, et al. (2007) Comparative fracture risk in vegetarians and nonvegetarians in EPIC-Oxford. Eur J Clin Nutr 61, 12, 1400-1406.

27. Martinez-Ramirez MJ, Palma S, Martinez-Gonzalez MA, et al. (2007) Dietary fat intake and the risk of osteoporotic fractures in the elderly. Eur J Clin Nutr 61, 9, 1114-1120.

28. Orchard TS, Cauley JA, Frank GC, et al. (2010) Fatty acid consumption and risk of fracture in the Women's Health Initiative. The American Journal of Clinical Nutrition 92, $6,1452-1460$.

29. Farina EK, Kiel DP, Roubenoff R, et al. (2011) Dietary Intakes of Arachidonic Acid and \{alpha\}-Linolenic Acid Are Associated with Reduced Risk of Hip Fracture in Older Adults. The Journal of nutrition 141, 6, 1146-1153.

30. Virtanen JK, Mozaffarian D, Cauley JA, et al. (2010) Fish consumption, bone mineral density, and risk of hip fracture among older adults: the cardiovascular health study. J Bone Miner Res 25, 9, 1972-1979.

31. Suzuki T, Yoshida H, Hashimoto T, et al. (1997) Case-control study of risk factors for hip fractures in the Japanese elderly by a Mediterranean Osteoporosis Study (MEDOS) questionnaire. Bone 21, 5, 461-467.

32. U.S. National Library of Medicine, National Institutes of Health (2011) OLDMEDLINE Data, http://www.nlm.nih.gov/ databases/databases_oldmedline.html. Accessed 10/21/11

33. Balshem H, Helfand M, Schunemann HJ, et al. (2011) GRADE guidelines: 3. Rating the quality of evidence. Journal of clinical epidemiology 64, 4, 401-406.

34. Terracciano L, Brozek J, Compalati E, et al. (2010) GRADE system: new paradigm. Current opinion in allergy and clinical immunology 10, 4, 377-383.

35. Cohen J (1988) Statistical Power Analysis for the Behavioral Sciences, 2nd ed. Hillsdale, NJ: Lawrence Erlbaum Assoc.

36. Rosnow RaRR (1996) Computing contrasts, effect sizes, and counternulls on other people's published data: general procedures for research consumers. Psych Meth 1, 331-340.

37. Hedges LaO I (1985) Statistical Methods for Meta-analys. New York, NY: Academic Press.

38. Martin-Bautista E, MuÃ \pm oz-Torres M, Fonolla J, et al. (2010) Improvement of bone formation biomarkers after 1-year consumption with milk fortified with eicosapentaenoic acid, docosahexaenoic acid, oleic acid, and selected vitamins. Nutrition research (New York, NY) 30, 5, 320-326.

39. Griel AE, Kris-Etherton PM, Hilpert KF, et al. (2007) An increase in dietary n-3 fatty acids decreases a marker of bone resorption in humans. Nutr J 6, 2 .

40. Kruger MC, Coetzer H, de Winter R, et al. (1998) Calcium, gamma-linolenic acid and eicosapentaenoic acid supplementation in senile osteoporosis. Aging (Milano) 10, 5 , 385-394.

41. Appleton KM, Fraser WD, Rogers PJ, et al. (2011) Supplementation with a low-moderate dose of n-3 long-chain PUFA has no short-term effect on bone resorption in human adults. The British journal of nutrition 105, 8, 1145-1149.

42. Salari Sharif $\mathrm{P}$, Asalforoush $M$ \& Ameri FThe effect of $n-3$ fatty acids on bone biomarkers in Iranian postmenopausal osteoporotic women: a randomized clinical trial. $A G E \mathbf{3 2}, 2$, 179-186

43. Dodin S, Lemay A, Jacques H, et al. (2005) The Effects of Flaxseed Dietary Supplement on Lipid Profile. Bone Mineral Density, and Symptoms in Menopausal Women: A Randomized, Double-Blind, Wheat Germ Placebo-Controlled Clinical Trial. J Clin Endocrinol Metab 90, 3, 1390-1397.

44. Cornish SM \& Chilibeck PD (2009) Alpha-linolenic acid supplementation and resistance training in older adults. Applied 
physiology, nutrition, and metabolism $=$ Physiologie appliquee, nutrition et metabolisme 34, 1, 49-59.

45. Bassey EJ, Littlewood JJ, Rothwell MC, et al. (2000) Lack of effect of supplementation with essential fatty acids on bone mineral density in healthy pre- and postmenopausal women: two randomized controlled trials of Efacal v. calcium alone. The British journal of nutrition 83, 6, 629-635.

46. Kolahi S, Ghorbanihaghjo A, Alizadeh S, et al. (2010) Fish oil supplementation decreases serum soluble receptor activator of nuclear factor-kappa B ligand/osteoprotegerin ratio in female patients with rheumatoid arthritis. Clinical Biochemistry 43, 6, 576-580.

47. Jackson RD, LaCroix AZ, Gass M, et al. (2006) Calcium plus Vitamin D Supplementation and the Risk of Fractures. $N$ Engl J Med 354, 7, 669-683.

48. Looker A, Melton L, Borrud L, et al. (2011) Changes in femur neck bone density in US adults between 1988â€"1994 and 2005â€"2008: demographic patterns and possible determinants. Osteoporosis International 1-10.

49. Robbins J, Aragaki AK, Kooperberg C, et al. (2007) Factors Associated With 5-Year Risk of Hip Fracture in Postmenopausal Women. JAMA 298, 20, 2389-2398.

50. Hay AW, Hassam AG, Crawford MA, et al. (1980) Essential fatty acid restriction inhibits vitamin D-dependent calcium absorption. Lipids 15, 4, 251-254.

51. Haag M, Magada ON, Claassen N, et al. (2003) Omega-3 fatty acids modulate ATPases involved in duodenal $\mathrm{Ca}$ absorption. Prostaglandins, Leukotrienes and Essential Fatty Acids 68, 6, 423-429.

52. Sun L, Tamaki H, Ishimaru T, et al. (2004) Inhibition of osteoporosis due to restricted food intake by the fish oils DHA and EPA and perilla oil in the rat. Biosci Biotechnol Biochem 68, 12, 2613-2615.

53. Zwart SR, Pierson D, Mehta S, et al. (2010) Capacity of omega-3 fatty acids or eicosapentaenoic acid to counteract weightlessness-induced bone loss by inhibiting NF-kappaB activation: from cells to bed rest to astronauts. J Bone Miner Res 25, 5, 1049-1057.

54. Watkins BA, Li Y \& Seifert MF (2001) Nutraceutical fatty acids as biochemical and molecular modulators of skeletal biology. J Am Coll Nutr 20, 5, 410S-416S, discussion 7S-20S.

55. Baggio B, Budakovic A, Nassuato MA, et al. (2000) Plasma phospholipid arachidonic acid content and calcium metabolism in idiopathic calcium nephrolithiasis. Kidney Int $\mathbf{5 8}$, 3, 1278-1284.

56. Haag M \& Kruger MC (2001) Upregulation of duodenal calcium absorption by poly-unsaturated fatty acids: events at the basolateral membrane. Medical bypotheses 56, 5, 637-640.

57. Leonard F, Haag M \& Kruger MC (2001) Modulation of intestinal vitamin D receptor availability and calcium ATPase activity by essential fatty acids. Prostaglandins Leukot Essent Fatty Acids 64, 3, 147-150. 